Journal of Patient-Centered

\title{
Problems Experienced in the First Month After Discharge From a Heart Failure-Related Hospitalization
}

Joan S. Grant

Lucinda J. Graven

Kelly Fuller

Follow this and additional works at: https://aah.org/jpcrr

Part of the Cardiology Commons, Cardiovascular Diseases Commons, Cardiovascular System Commons, and the Dietetics and Clinical Nutrition Commons

\section{Recommended Citation}

Grant JS, Graven LJ, Fuller K. Problems experienced in the first month after discharge from a heart failurerelated hospitalization. J Patient Cent Res Rev. 2018;5:140-8. doi: 10.17294/2330-0698.1588

Published quarterly by Midwest-based health system Advocate Aurora Health and indexed in PubMed Central, the Journal of Patient-Centered Research and Reviews (JPCRR) is an open access, peer-reviewed medical journal focused on disseminating scholarly works devoted to improving patient-centered care practices, health outcomes, and the patient experience. 


\title{
Problems Experienced in the First Month After Discharge From a Heart Failure-Related Hospitalization
}

\author{
Joan S. Grant, PhD, RN, ${ }^{1}$ Lucinda J. Graven, PhD, MSN, ARNP, ${ }^{2}$ Kelly Fuller, BSN, RN² \\ ${ }^{1}$ University of Alabama at Birmingham School of Nursing, Birmingham, AL; ${ }^{2}$ Florida State University College of Nursing, \\ Tallahassee, FL
}
Purpose Heart failure is a global health concern with high morbidity and mortality rates. Individuals with heart failure commonly experience problems that impact daily life. However, little is known regarding which problems are most significant during the immediate posthospitalization period. Thus, the purpose of this study was to identify high-priority problems experienced by individuals the first month after discharge from an acute care facility with a diagnosis of heart failure.

Methods $\quad$ This descriptive, exploratory study was part of a 12-week randomized controlled pilot study that
examined the efficacy of a coping partnership intervention (COPE-HF Partnership) between a trained
research nurse and individuals with heart failure in managing self-care and depressive symptoms.
Data from participants randomized to the intervention group ( $\mathrm{N}=19 ; 58 \%$ Caucasian, $58 \%$ male) were
used in this study. Participants were provided a list of potential heart failure-related problems, from
which they identified those of highest priority. Content and quantitative data analysis was conducted.

Results Difficulty in managing heart failure symptoms, adhering to treatment plan, completing daily activities, and experiencing negative emotions and moods were the most common problems experienced by individuals with heart failure. Other less common problems for the group were inadequate resources and managing interpersonal issues.

Conclusions Individuals with heart failure experience complex problems in the home that impact all aspects of their lives. Incorporating strategies to address these problems could assist in the development of interventions to reduce negative heart failure outcomes. (J Patient Cent Res Rev. 2018;5:140-148.)

Keywords heart failure; problems; postdischarge; hospitalization; morbidity; mortality; symptoms

$\mathrm{H}$ eart failure (HF) is a global public health concern, affecting approximately 5.7 million individuals in the United States ${ }^{1}$ and 26 million worldwide. $^{2}$ Although mortality rates have declined, approximately $50 \%$ of individuals diagnosed with $\mathrm{HF}$ continue to die within 5 years of diagnosis. ${ }^{1} \mathrm{HF}$ remains the most common reason for hospital readmissions within 30 days of discharge, ${ }^{3}$ with direct and indirect costs exceeding $\$ 30$ billion dollars annually. ${ }^{1}$ As the general population ages, the estimated prevalence and cost of care for HF will increase substantially. ${ }^{4}$

Correspondence: Joan S. Grant, PhD, RN, University of Alabama at Birmingham School of Nursing, 1701 University Boulevard, Birmingham, AL 35294-1210 (grantj@uab.edu)
$\mathrm{HF}$ is stressful, ${ }^{5}$ and individuals with heart failure (IHF) frequently experience dyspnea, edema, fatigue, sleeplessness, ${ }^{6,7}$ and activity intolerance that impacts their functional ability. ${ }^{8-10} \mathrm{Up}$ to $60 \%$ of IHF reportedly forget to take their HF medications. ${ }^{11}$ IHF also manage multiple medications and comorbidities and experience ineffective communication with health providers. ${ }^{12}$ The psychological sequelae of HF are significant, and many individuals experience depression ${ }^{13}$ and negative emotions and mood, such as anxiety, fear, and irritability. ${ }^{6}$ Unmet financial needs, ${ }^{14}$ inadequate psychosocial support, ${ }^{12,15}$ and social isolation ${ }^{9}$ further compound these problems in the home.

IHF experience complex problems in the home that impact all aspects of their lives. Yet, empirical literature regarding high-priority problems in the immediate 
posthospitalization period is limited. Thus, the purpose of this study was to identify high-priority problems experienced by IHF in the first month after discharge from an acute care facility with a diagnosis of HF.

\section{METHODS}

\section{Design, Participants, and Setting}

This descriptive, exploratory study was part of a 12week randomized controlled pilot study that examined the efficacy of a coping partnership intervention (COPEHF Partnership), primarily delivered over the telephone, on HF self-care and depressive symptoms. ${ }^{16}$ The COPE-HF Partnership intervention trained IHF to use social problem-solving skills to manage common highpriority problems associated with $\mathrm{HF}$ after discharge to home. Participants $(\mathrm{N}=19)$ who were assigned to the intervention group participated in this study. A detailed description of the intervention and corresponding protocol is available elsewhere. ${ }^{16}$ Information relevant to the current study is provided herein.

Participants were recruited during an acute care admission for HF from two local facilities that serve a diverse population regarding gender, ethnicity, and socioeconomic status from a 4-county, predominantly rural area. Participants were included if they were 1) undergoing treatment for $\mathrm{HF}, 2$ ) reachable by telephone, 3) able to speak English and hear well enough to engage in phone contacts, and 4) 18 years of age or older. IHF were excluded from the study if they had 1) a diagnosis of HF due to a correctable cause or condition, 2) illnesses that were associated with a reduced life expectancy of $<12$ months, or 3) a history of psychoses, dementia, or cognitive impairment.

Prior to enrollment, participants were screened for cognitive impairment using the Six-Item Cognitive Impairment Test. ${ }^{17}$ Individuals with scores 8 or higher were excluded from participation due to the possibility of cognitive impairment. ${ }^{17}$

\section{Instruments}

Sociodemographic and clinical information were collected via self-report to assess key participant characteristics (age, gender, race, etc) using a researcher-developed survey. Clinical information included the severity of HF (ie, New York Heart Association [NYHA] classification), length of time since HF diagnosis, and comorbidities (ie, Charlson comorbidity index). ${ }^{18}$ Data related to problems experienced by individuals with HF were recorded on a data form, which specified participant identification numbers and the intervention week (that is, 1-4).

\section{Procedure}

The appropriate institutional review boards approved the study prior to recruitment. The intervention consisted of an initial 1.5-hour home visit 1 week after discharge. During this initial session, a trained nurse interventionist provided education relative to social problem-solving and instructed IHF in using these skills to manage and cope with problems and stressors. IHF learned effective skills in which to view feelings about their HF (ie, problem orientation) and to identify and solve problems using a 4-step problem-solving process. ${ }^{16,19}$ To provide standardization of content, IHF practiced applying problem-solving skills to the problem of fatigue during the home visit (because about $50 \%$ of IHF experience fatigue ${ }^{20}$ ).

After practicing social problem-solving skills during the home visit, participants were provided with a set of 7 cards representing common HF problems identified from empirical literature. These problems included HF symptoms (eg, shortness of breath [SOB], fatigue), HF-related treatment regimen (eg, adhering to fluid restriction and low-salt diet, measuring weight daily, exercise participation), interpersonal and social issues (eg, lack of social support), daily activities (eg, activity intolerance, impaired sleep), mood (eg, depressive symptoms, anxiety), resource difficulties (eg, inadequate information about HF, financial problems), and other. ${ }^{13,21}$ The "other" card represented problems not denoted on the previous 6 cards, but were problems identified by HF participants during contacts. Participants were asked to use these cards to identify and prioritize problems that were currently most significant.

The home visit was followed by 3 weekly telephone contacts for the first month and conducted by the trained nurse interventionist. During each followup phone contact, IHF were asked to identify highpriority problems they were experiencing since the last contact, using the set of 7 cards. Both current and newly identified problems were examined during the phone contacts. The nurse interventionist and a trained research assistant randomly listened to phone contacts 
and compared information recorded on the data form and problems identified by IHF. To ensure credibility of data, data were collected concurrently with problem prioritization on a data form during the home visit and each phone contact by the nurse interventionist and trained research assistant. Accuracy of identified problems was confirmed at the end of each contact. Further, identified problems from previous contacts (eg, week 2) were reviewed with IHF at the beginning of subsequent phone contacts (eg, week 3) before identifying any new priority problems for the current week. Conversations were not recorded, but extensive field notes were taken during the contacts by the research assistant to confirm and add understanding to problems.

\section{Statistical Analysis}

Data analysis was conducted using SPSS Statistics Version 22.0 (IBM Corporation, Armond, NY). Demographic data were analyzed using mean and standard deviation (SD), or frequency and percentage for nominal variables. Content and quantitative data analyses were used to identify problems experienced by IHF from field notes taken during interviews. These problems were independently analyzed and coded by two content experts. Differences were discussed until consensus was achieved on the final list of problems. Two other content experts randomly analyzed problems and field notes further for accuracy.

\section{RESULTS}

Mean age of participants was 61.0 years (SD: 14.5). Most were unmarried $(\mathrm{n}=13,68.4 \%)$, Caucasian $(\mathrm{n}=11$, $57.9 \%)$, male ( $\mathrm{n}=11,57.9 \%)$, and high school educated $(\mathrm{n}=13,68.4 \%)$. Typically, 1-2 people resided in the home with the IHF $(n=11,57.9 \%)$. Most participants had a HF diagnosis for less than 1 year $(n=10,52.6 \%)$ and were NYHA class II $(n=10,52.6 \%)$. Number of comorbidities ranged from zero to 5 , with $1(\mathrm{n}=5$, $26.3 \%)$ or $2(\mathrm{n}=5,26.3 \%)$ the most common (Table 1$)$.

Problems experienced by IHF were interrelated, influencing one or more other problems identified during each contact. Field notes made during contacts provided very rich data for understanding these problems. Table 2 summarizes the frequency of the high-priority problems.

\section{Week 1}

Difficulty in managing HF symptoms $(n=13)$ was the highest-priority problem identified by participants.
Table 1. Demographics and Descriptive Statistics $(\mathrm{N}=19)$

\begin{tabular}{|c|c|}
\hline Demographic & n (\%) \\
\hline Age, mean (SD) & 61 years $(14.5)$ \\
\hline \multicolumn{2}{|l|}{ Gender } \\
\hline Female & $8(42.1 \%)$ \\
\hline Male & $11(57.9 \%)$ \\
\hline \multicolumn{2}{|l|}{ Race } \\
\hline African American & $8(42.1 \%)$ \\
\hline Caucasian & $11(57.9 \%)$ \\
\hline \multicolumn{2}{|l|}{ Marital status } \\
\hline Married & $6(31.6 \%)$ \\
\hline Unmarried & $13(68.4 \%)$ \\
\hline \multicolumn{2}{|l|}{ Education level } \\
\hline 6th-9th grade & $1(5.3 \%)$ \\
\hline High school graduate & $13(68.4 \%)$ \\
\hline College graduate & $5(26.3 \%)$ \\
\hline \multicolumn{2}{|c|}{ Number of people in house } \\
\hline $1-2$ & $11(57.9 \%)$ \\
\hline $3-4$ & $7(36.8 \%)$ \\
\hline$>5$ & $1(5.3 \%)$ \\
\hline \multicolumn{2}{|l|}{ Years since HF diagnosis } \\
\hline$<1$ year & $10(52.6 \%)$ \\
\hline $1-5$ years & $5(26.3 \%)$ \\
\hline $6-10$ years & $1(5.3 \%)$ \\
\hline $11-15$ years & $2(10.5 \%)$ \\
\hline$>15$ years & $1(5.3 \%)$ \\
\hline \multicolumn{2}{|l|}{ NYHA HF class } \\
\hline I & $3(15.8 \%)$ \\
\hline II & $10(52.6 \%)$ \\
\hline III & $1(5.3 \%)$ \\
\hline IV & $5(26.3 \%)$ \\
\hline \multicolumn{2}{|l|}{ Number of comorbidities* } \\
\hline 0 & $4(21.1 \%)$ \\
\hline 1 & $5(26.3 \%)$ \\
\hline 2 & $5(26.3 \%)$ \\
\hline 3 & $4(21.1 \%)$ \\
\hline 4 & $0(0 \%)$ \\
\hline 5 & $1(5.3 \%)$ \\
\hline
\end{tabular}

HF symptoms, such as fatigue, activity intolerance, tiredness, lightheadedness, SOB, forgetfulness, subjective memory problems, and heart palpitations, were challenging for IHF. Some individuals felt fatigued even while sitting. IHF also reported other problematic symptoms, including a consistent dry 
Table 2. Frequency of Problems Reported by Week

\begin{tabular}{lcccc}
\hline Problems & Week 1 & Week 2 & Week 3 & Week 4 \\
\hline Heart failure symptoms & 13 & 9 & 9 & 10 \\
Treatment regimen & 12 & 14 & 12 & 15 \\
Daily activities & 12 & 6 & 2 & 5 \\
Mood & 12 & 7 & 7 & 5 \\
Resources & 4 & 4 & 4 & 3 \\
Interpersonal/social & 2 & 4 & 1 & 1 \\
Other issues & 1 & 2 & 1 & 0 \\
\hline
\end{tabular}

cough and sleep difficulties from SOB while sleeping on their back. IHF reported sleeping in a recliner as one way to adapt to sleep difficulties. SOB was severe for some, interfering with their eating, talking, and activities. Subjective memory problems also were a challenge, with some IHF forgetting to perform self-care activities such as checking capillary blood glucose.

Managing treatment regimen, completing daily activities, and experiencing negative moods $(n=12$ for each of problem) were rated equally as the secondhighest priority. Notably, this priority rating was almost identical to that of managing HF symptoms, emphasizing their importance to IHF. Managing their dietary regimen was the primary concern related to treatment regimen mentioned by IHF. Issues such as adhering to a healthy diet; restricting sodium, fluid, and cholesterol intake; and monitoring their weight were frequently reported. Lack of knowledge about their diet plan was a significant problem for IHF. While IHF had information from the hospital regarding their diet, they needed assistance to understand or process the information. Other IHF had difficulty reading food labels, understanding that both salt and sodium were important to restrict, and lacked knowledge related to foods and fluids that contained higher amounts of sodium. While some IHF were unsure of their sodium restriction, they reportedly knew not to use salt. Several IHF or their respective caregivers reportedly did not know how to cook without salt and requested low-salt recipes. Some IHF felt they were not eating enough due to their low-sodium diet, while others felt they needed to become accustomed to eating differently. Other issues relative to treatment plan included smoking cessation, managing multiple medications, exercising, and eliminating caffeine.
IHF reported difficulty completing daily activities. While some of these activities were instrumental activities of daily living, such as housework and shopping, others were pleasurable activities that gave significant meaning to their daily life. These activities were greatly impaired due to HF symptoms such as fatigue, low energy levels, SOB, and activity intolerance. While IHF desired to do pleasurable activities that added meaning to their life (eg, feed fish in the pond, gardening), HF symptoms prevented these activities. Although IHF disliked inactivity, several stated that they did not have the energy to participate in their usual hobbies or activities. Participating in family events also was difficult due to decreased energy or negative emotions and moods. Some IHF felt uncertainty and wanted to know recommendations regarding safe limits to their daily activities, including safe job activities if they continued to be employed.

Another major problem identified by IHF was negative emotions and moods, for example, depression, feeling down, anxiety, being grumpy, and decreased motivation and quality of life. Individuals reported mood swings similar to a roller coaster, especially when attempting to participate in pleasurable activities only to realize that they no longer had the energy to participate. IHF reported feeling depressed due to worrying about their disease and trying to manage multiple comorbidities in addition to HF. Others were anxious, worrying about new treatment regimens and whether they would be successful. A limited ability to participate in pleasurable activities (eg, working in the garden) also negatively affected their quality of life. IHF sought pleasurable moments that elevated their negative mood. For some IHF, anticipating future morbidity contributed to depression and anxiety. For those IHF returning to work, depression continued after they returned to their job. 
While inadequate resources $(n=4)$ was rated as the third-highest priority, a smaller number of IHF reported this problem, experiencing financial issues in paying for household and medical bills or healthy foods that satisfied their dietary regimen. Some IHF reportedly lost their employment because HF symptoms (eg, fatigue) interfered with their job duties. Inadequate knowledge about available resources in their local communities also was identified.

Other less common problems experienced by IHF as a group during the first week were interpersonal and social issues, which include lack of social support, transportation to health provider appointments, and impaired relationships with family members.

\section{Week 2}

Managing treatment regimen $(n=14)$ was the main problem identified by IHF in the second week, with implementing their dietary regimen still the major concern. These concerns continued to evolve around limiting salt intake and fluids and monitoring weight. While some IHF remained overwhelmed trying to select foods to eat, others actively implemented recommended strategies such as eating small meals and utilizing community food programs. Other treatment regimen problems pertained to monitoring daily weight because some IHF did not own a personal scale.

Difficulty in managing HF symptoms ( $\mathrm{n}=9$ ) was the second-highest-priority problem, with reports of edema, fatigue, forgetfulness, SOB, nausea, lightheadedness, and cough persisting. Fatigue remained the top symptom complaint, with $\mathrm{SOB}$ being problematic during strenuous activity. Some IHF reported improved SOB with rest and oxygen, while others reported forgetfulness as a problem more often this week.

Negative emotions and moods $(n=7)$ was the thirdhighest-priority problem reported during the second week. Depression, feeling down, anxiety, being grumpy, and decreased motivation and quality of life were common. Some IHF blamed their negative moods on a change in their active lifestyle. Others associated their negative moods with an uncertain future. Dietary regimen also contributed to anxiety in determining what to eat. Some IHF dealt with negative emotions and moods by making conscious efforts to do more enjoyable activities and visit friends and relatives.
The inability to complete daily activities $(n=6)$ remained problematic. While fatigue was a major contributing factor in difficulty completing daily activities, participants recognized the need to implement daily activities in small increments. IHF also reported that consistent exercise provided more energy to complete these activities versus the previous week. IHF continued to report inadequate resources and interpersonal and social issues, similar to the first week. Financial resources were constrained for employed IHF due to missed work. Often, IHF were waiting for approval of governmental assistance. New interpersonal and social issues related to situations where friends and family verbally offered assistance but failed to carry through with actual physical assistance.

\section{Week 3}

Managing treatment regimen $(n=12)$ continued to be the top problem in week 3 . Although diet remained a significant issue, IHF were more active in eating small meals and trying to identify new foods and spices that added variety to their diet. IHF also actively "chose" restaurants where they could eat appropriate meals. Exercise participation and outside activities were now major issues. IHF actively attempted to do outside activities, albeit at a slower pace and with frequent rest periods. Some IHF continued to report forgetting to take scheduled medications, not weighing daily, and difficulty with smoking cessation. However, overall, the third week appeared to be a turning point for many IHF. IHF were more proactive in evaluating their problems positively and actively implementing strategies to solve those problems.

The second most common problem continued to be difficulty managing HF symptoms $(n=9)$. Fatigue remained the most problematic symptom for most IHF, with waxing and waning of energy levels. Fatigue impacted daily activities, with some IHF still reporting SOB with activity. Yet, the majority of IHF reportedly were able to work within their limitations by interspersing activity with rest periods. Forgetfulness was a significant problem, with IHF forgetting words to use in conversations. Sleep was an issue for IHF, with some using continuous positive airway pressure (CPAP) for sleep apnea and others taking prescribed sleeping agents.

The third-highest problem reported was negative emotions and moods $(n=7)$. Some IHF reported crying 
spells. Others indicated their quality of life was poor because of fatigue. Anxiety was prevalent, as some IHF were unable to pay bills or afford prescribed heart medications. However, IHF were overall more positive regarding their mood, with most reporting less depressive symptoms and implementation of strategies to improve negative mood.

IHF continued to express problems as a group in completing daily activities and inadequate resources. While fatigue continued to be a major issue and IHF still had difficulty doing housework and other outside activities, the group overall was active in interspersing activity with rest. Paying bills was a major concern, but IHF were hesitant to ask for assistance from family and friends because of their independence. Others verbalized a lack of social support and had difficulty finding someone to provide transportation to their health provider.

\section{Week 4}

Understanding and managing treatment regimen $(n=15)$ continued to be the highest-priority problem during week 4. Fluid and sodium restriction and appropriate foods to eat were major concerns. Some IHF experienced a loss of appetite, complaining that the food tasted different. However, overall, IHF as a group were more comfortable with the low-sodium diet and voiced both good and bad days regarding diet. IHF were able to note the consequences of not following their diet and fluid restrictions (ie, increased pedal edema, more SOB). Most IHF had family members that monitored what the IHF ate. Holidays were particularly problematic because some family members added salt when cooking and IHF reported lack of control of the available food.

By week 4, IHF were more proactive regarding managing their own medications. Some IHF used phone reminders and timers to reinforce medication adherence. Others wrote down medications and when they took them. Some IHF were working with physical therapy and personal trainers to develop exercise plans, while others developed their own plans through experience. A few IHF still did not own a scale due to limited finances and were not able to take a daily weight. Frequent toileting due to diuretics also was an issue, and health providers subsequently scheduled IHF to take diuretics at earlier times during the day. Smoking cessation was still a challenge for those who had smoked for many years.
The second most common problem was difficulty in managing HF symptoms $(\mathrm{n}=10)$. Heart palpitations and SOB were present in some IHF, interfering with sleep and activities of daily living. Fatigue was improving for the majority of IHF. Problems with sleep were still present. CPAP appeared to improve the quality but not the quantity, with IHF sleeping for short periods of time. Forgetting whether medications had been taken was still a problem. However, most IHF used pill containers, which prevented double dosing.

Negative emotions and moods $(n=5)$ and difficulty in completing daily activities $(n=5)$ were rated equally by IHF as the third-highest-priority problem during week 4. Negative emotions and moods continued despite antidepressants, with some still describing crying spells. Activity intolerance remained a major problem, interfering with daily activities. Some IHF reported making themselves get up and move around 4-5 times a day and participate in more outside activities. More IHF readily paced themselves, alternating activities with rest. Stamina and energy varied daily among IHF, and they were better able to mentally and physically adjust routines around the varied energy levels.

Other less common problems reported were inadequate resources and interpersonal and social issues. Negative emotions and moods, HF symptoms, inadequate resources, and interpersonal and social issues were interrelated. IHF voiced that they were unable to do daily activities with friends because of inadequate monies. IHF also feared they would experience fatigue or activity intolerance during shopping or outings if they went. Inadequate resources (eg, monies) also prevented some IHF from buying healthy foods. IHF were often waiting on governmental assistance to buy prescriptions, while others arranged a payment schedule to pay a limited amount each month on medical bills.

\section{DISCUSSION}

While empirical literature indicates IHF experience complex problems in the home, studies that identify problems viewed as high priority by IHF in the immediate posthospitalization period are limited. Our findings support those of previous studies that indicated uncertainty is prevalent in the lives of IHF, ${ }^{22-}$

${ }^{24}$ occurs very early in HF and includes feelings of confusion, being overwhelmed, and a loss of control. 
Similar to findings of others, ${ }^{23,25}$ HF symptoms (eg, fatigue, activity intolerance) significantly influenced completion of daily activities, depression, and social activities the first 4 weeks postdischarge. Findings of this study agree with prior research that identified fatigue and $\mathrm{SOB},{ }^{26}$ plus comorbidities, ${ }^{27}$ as major contributors related to interference with daily activities and social activities as well as a factor related to increased reports of depression. However, while some IHF were learning to monitor their HF symptoms internally and to integrate a recommended treatment regimen into their daily lives, the first month was characterized by IHF being overwhelmed with life changes related to HF.

It is well known that subjective memory problems are common in $\mathrm{HF} ;{ }^{28}$ however, our findings indicate that they may occur early in HF. Studies have suggested that calcium channel blockers and loop diuretics may be contributing factors to forgetfulness in IHF. ${ }^{29}$ Although resources (financial, social) and interpersonal problems appeared to be a problem for fewer individuals the first month posthospitalization, many were waiting for governmental assistance with their finances.

Dietary regimen was a significant part of patients' treatment plan, which many IHF initially failed to understand and found confusing. Similar to other studies, ${ }^{30}$ many IHF did not realize the importance of reading food labels for sodium and salt content. Some participants did not purchase a home scale for 3 to 4 weeks, emphasizing the importance of proving additional education regarding the significance of monitoring daily weight and inquiring whether the IHF has a scale prior to discharge. However, while empirical data indicate IHF assigned to an intervention group often weigh themselves more, ${ }^{31}$ daily weight may not improve rehospitalization or mortality. ${ }^{32}$ Although exercising appeared to be challenging initially due to HF symptoms, its implementation improved over 4 weeks.

Managing symptoms was higher priority in week 1, whereas managing treatment regimen was the highest priority during weeks 2-4. However, managing HF symptoms was rated very closely to that of managing treatment regimen, completing daily activities, and experiencing negative moods during the first week, indicating IHF viewed all of these problems with high importance immediately after discharge. Other research indicates hospital discharge following a chronic illness is overwhelming and full of challenges, with attempts by IHF to transition from an illness-defined experience to a "normal" life as quickly as possible. ${ }^{33}$ Consistent with previous research, IHF viewed many problems as high priority during the transition from hospital to home yet gave priority to managing HF symptoms during the first week. ${ }^{13,34}$ During weeks 2-4, IHF were better able to prioritize their problems on treatment regimens that potentially would improve their $\mathrm{HF}$ symptoms and quality of life.

\section{Limitations}

While this study provides insight into problems deemed highest priority by IHF in the immediate posthospitalization period, limitations exist that impact generalizability of study findings. Study design resulted in a small sample size of patients recently discharged from the hospital, thereby limiting generalizability. Further, patients were excluded if they had difficulty hearing on the phone. This criterion may have inadvertently excluded patients who were experiencing depression or nonadherence due to hearing loss.

Although a strong methodology was used for the intervention component, the actual experience of participating in the COPE-HF Partnership intervention may have influenced the high-priority problems reported by IHF. While the range of years since diagnosis of HF was broad $(<1$ to $>15)$, the duration for most participants was less than 1 year and may have influenced the types of problems experienced by IHF. Additionally, most participants had NYHA class II HF, which may have influenced the severity and characteristics of the reported problems the first month postdischarge. Thus, more research investigating problems experienced by a more diverse group of IHF are needed.

\section{Relevance to Practice}

Consistent with other literature, ${ }^{8-15}$ IHF experience both cardiac (eg, difficulty in managing HF symptoms) and noncardiac (eg, inadequate resources and managing interpersonal issues) high-priority problems after discharge from the hospital to home. Many of these problems are interrelated. Initially, IHF and their families should be given discharge instructions and literature regarding HF symptoms, their treatment regimen, daily activities, and mood and emotions experienced after HF. 
However, information regarding these problems and their interrelationship to each other (eg, how fatigue affects self-care activities and possible adaptations) may be best processed later (ie, weeks 2-4). This information could be offered through home visits, phone contacts, email messages, and internet resources. ${ }^{35}$ Online education and coaching programs promoting HF selfcare also appear promising. ${ }^{36}$ Mobile phone applications (HeartMapp), which include daily alerts (eg, check weight, medication), assessment (eg, HF symptoms), audio and visual feedback, and patient education (eg, diet, self-care, activities) designed to promote self-care and improve long-term outcomes, are now available. ${ }^{37}$

\section{CONCLUSIONS}

This study indicates individuals with heart failure experience complex problems in the home that can impact all aspects of their lives, with some problems deemed more significant than others. HF symptoms, treatment regimen, and negative emotions and moods were consistently reported as high-priority problems in the immediate posthospitalization period. Moreover, negative emotions and moods, HF symptoms, inadequate resources, and interpersonal and social issues were found to be interrelated problems. More research on posthospitalization problems experienced by individuals with HF is needed to support findings of this study and influence the development of interventions to reduce negative outcomes.

\section{Patient-Friendly Recap}

- Individuals diagnosed with heart failure experience complex problems in the home that impact aspects of their daily lives.

- A group of these patients was asked to prioritize the problems they encountered within a month of being discharged from the hospital.

- The authors found that individuals with heart failure have difficulty managing symptoms, adhering to their treatment plan, and performing daily activities. They also experience negative emotions and moods.

- Future interventions designed to improve health outcomes in patients with heart failure - and reduce readmissions to the hospital — should account for high-priority home-based issues.

\section{Author Contributions}

Study design: Grant, Graven. Data acquisition and/or analysis: all authors. Manuscript drafting: Grant, Graven. Critical revision: Grant, Graven.

\section{Conflicts of Interest}

None.

\section{Funding Sources}

This work was funded by an American Nurse Practitioners Foundation nursing research grant and a Florida State University First Year Assistant Professor grant. The funders had no role in study design, data collection and analysis, decision to publish, or preparation of the manuscript.

\section{References}

1. Mozaffarian D, Benjamin EJ, Go AS, et al. Heart disease and stroke statistics - 2016 update: a report from the American Heart Association. Circulation. 2016;133:e38-60. CrossRef

2. Ambrosy PA, Fonarow GC, Butler J, et al. The global health and economic burden of hospitalizations for heart failure: lessons learned from hospitalized heart failure registries. J Am Coll Cardiol. 2014;63:1123-33. CrossRef

3. Arora S, Patel P, Lahewala S, et al. Etiologies, trends, and predictors of 30-day readmission in patients with heart failure. Am J Cardiol. 2017;119:760-9. $\underline{\text { CrossRef }}$

4. Heidenreich PA, Albert NM, Allen LA, et al. Forecasting the impact of heart failure in the United States: a policy statement from the American Heart Association. Circ Heart Fail. 2013;6:606-19. CrossRef

5. American Heart Association. Help for heart failure caregivers. http://www.heart.org/HEARTORG/Conditions/ HeartFailure/LivingWithHeartFailureAndAdvancedHF/ Help-For-Heart-Failure-Caregivers_UCM_306366_Article. jsp\#.WrqPmS7wa71. Accessed August 7, 2017.

6. Cameron J, Rhodes KL, Ski CF, Thompson DR. Carers' views on patient self-care in chronic heart failure. $J$ Clin Nurs. 2016;25:144-52. CrossRef

7. Johansson P, Broström A, Sanderman R, Jaarsma T. The course of sleep problems in patients with heart failure and associations to rehospitalizations. J Cardiovasc Nurs. 2015;30:403-10. CrossRef

8. Kessing D, Denollet J, Widdershoven J, Kupper N. Fatigue and self-care in patients with chronic heart failure. Eur $J$ Cardiovasc Nurs. 2016;15:337-44. CrossRef

9. Kraai IH, Vermeulen KM, Hillege HL, Jaarsma T. Perception of impairments by patients with heart failure. Eur $J$ Cardiovasc Nurs. 2016;15:178-85. CrossRef

10. Stevenson CW, Pori D, Payne K, Black M, Taylor VE. Hearing the veteran's voice in congestive heart failure readmissions. Prof Case Manag. 2015;20:177-85; quiz 186-7. CrossRef

11. Aggarwal B, Pender A, Mosca L, Mochari-Greenberger H. Factors associated with medication adherence among heart failure patients and their caregivers. J Nurs Educ Pract. 2015;5:22-7. CrossRef

12. Pattenden JF, Roberts H, Lewin RJ. Living with heart failure; patient and carer perspectives. Eur J Cardiovasc Nurs. 2007;6:273-9. CrossRef 
13. Graven LJ, Grant JS, Gordon G. Symptomatology and coping resources predict self-care behaviors in middle to older age patients with heart failure. Nurs Res Pract. 2015;2015:840240. CrossRef

14. Hamilton H. The lived experience of African American caregivers caring for adult African American patients with heart failure. Home Healthc Now. 2016;34:196-202.

15. Clark AM, Spaling M, Harkness K, et al. Determinants of effective heart failure self-care: a systematic review of patients' and caregivers' perceptions. Heart. 2014;100:716-21. CrossRef

16. Graven LJ, Gordon G, Grant Keltner J, Abbott L, Bahorski J. Efficacy of a social support and problem-solving intervention on heart failure self-care: a pilot study. Patient Educ Couns. 2018;101:266-75. CrossRef

17. Brooke P, Bullock R. Validation of a 6 item cognitive impairment test with a view to primary care usage. Int $J$ Geriatr Psychiatry. 1999;14:936-40. CrossRef

18. Charlson ME, Pompei P, Ales KL, MacKenzie CR. A new method of classifying prognostic comorbidity in longitudinal studies: development and validation. $J$ Chronic Dis. 1987;40:373-83. $\underline{\text { CrossRef }}$

19. D'Zurilla TJ, Nezu AM, Maydeu-Olivares A. Social ProblemSolving Inventory - Revised (SPSI-R). North Tonawanda, NY: Multi-Health Systems Inc., 2002.

20. Evangelista LS, Moser DK, Westlake C, Pike N, TerGalstanyan A, Dracup K. Correlates of fatigue in patients with heart failure. Prog Cardiovasc Nurs. 2008;23:12-7. CrossRef

21. Greenhalgh T, A'Court C, Shaw S. Understanding heart failure; explaining telehealth - a hermeneutic systematic review. BMC Cardiovasc Disord. 2017;17:156. CrossRef

22. Olano-Lizarraga M, Oroviogoicoechea C, Errasti-Ibarrondo B, Saracíbar-Razquin M. The personal experience of living with chronic heart failure: a qualitative meta-synthesis of the literature. J Clin Nurs. 2016;25:2413-29. CrossRef

23. Pihl E, Fridlund B, Mårtensson J. Patients' experiences of physical limitations in daily life activities when suffering from chronic heart failure; a phenomenographic analysis. Scand J Caring Sci. 2011;25:3-11. CrossRef

24. Seah AC, Tan KK, Huang Gan, JC, Wang W. Experiences of patients living with heart failure: a descriptive qualitative study. J Transcult Nurs. 2016;27:392-9. CrossRef

25. Schjoedt I, Sommer I, Bjerrum MB. Experiences and management of fatigue in everyday life among adult patients living with heart failure: a systematic review of qualitative evidence. JBI Database System Rev Implement Rep. 2016;14:68-115. $\underline{\text { CrossRef }}$
26. Falk H, Ekman I, Anderson R, Fu M, Granger B. Older patients' experiences of heart failure - an integrative literature review. J Nurs Scholarsh. 2013;45:247-55. CrossRef

27. Fry M, McLachlan S, Purdy S, Sanders T, Kadam UT, ChewGraham CA. The implications of living with heart failure; the impact on everyday life, family support, co-morbidities and access to healthcare: a secondary qualitative analysis. $B M C$ Fam Pract. 2016;17(1):139. CrossRef

28. Murad K, Goff DC Jr, Morgan TM, et al. Burden of comorbidities and functional and cognitive impairments in elderly patients at the initial diagnosis of heart failure and their impact on total mortality: the Cardiovascular Health Study. JACC Heart Fail. 2015;3:542-50. CrossRef

29. RuDusky BM. Heart failure and comorbidities. JACC Heart Fail. 2015;3:1003. CrossRef

30. Spaling MA, Currie K, Strachan PH, Harkness K, Clark AM. Improving support for heart failure patients: a systematic review to understand patients' perspectives on self-care. J Adv Nurs. 2015;71:2478-89. CrossRef

31. Veroff DR, Sullivan LA, Shoptaw EJ, et al. Improving selfcare for heart failure for seniors: the impact of video and written education and decision aids. Popul Health Manag. 2012;15:37-45. CrossRef

32. Lyngå P, Persson H, Hägg-Martinell A, et al. Weight monitoring in patients with severe heart failure (WISH). A randomized controlled trial. Eur J Heart Fail. 2012;14:438-44. CrossRef

33. Cain CH, Neuwirth E, Bellows J, Zuber C, Green J. Patient experiences of transitioning from hospital to home: an ethnographic quality improvement project. J Hosp Med. 2012;7:382-7. CrossRef

34. Graven LJ, Grant JS, Vance DE, Pryor ER, Grubbs L, Karioth S. Predicting depressive symptoms and self-care in patients with heart failure. Am J Health Behav. 2015;39:77-87. CrossRef

35. Adib-Hajbaghery M, Maghaminejad F, Abbasi A. The role of continuous care in reducing readmission for patients with heart failure. J Caring Sci. 2013;2:255-67.

36. Stut W, Deighan C, Cleland JG, Jaarsma T. Adherence to self-care in patients with heart failure in the HeartCycle study. Patient Prefer Adherence. 2015;9:1195-206. CrossRef

37. Athilingam P, Clochesy JM, Labrador MA. Intervention mapping approach in the design of an interactive mobile health application to improve self-care in heart failure. Comput Inform Nurs. 2017;36:90-7. CrossRef

(C) 2018 Aurora Health Care, Inc. 